\title{
The Potential Causality of the Microbiome and Infectious Pathogens in Primary Vasculitis
}

\author{
Catherine Garcia $\cdot$ John D. Carter • Yih Chang Lin
}

Published online: 24 September 2014

(C) Springer International Publishing AG 2014

\begin{abstract}
Aberrant and dysregulated inflammation of human blood vessels, or vasculitis, results in narrowing of the vessel's lumen (i.e., stenosis) or aneurysmal wall damage (i.e., sac-like deformity of the vessel wall). This heterogenous group of autoimmune conditions is very rare. The understanding of the potential role of microbiome and infectious pathogens in eliciting immunologic responses and disease pathogenesis is rapidly expanding in many disease states. The precise role of microbiota in vasculitis is yet to be determined, but poses an interesting field of research. Our focus is on the potential role that infections and the microbiome may play in blood vessel inflammation, i.e., vasculitis.
\end{abstract}

Keywords Microbiome $\cdot$ Vasculitis · Infections ·

Autoimmune disease

\section{Introduction}

Human blood vessels are one of the largest organ systems in the body, reaching every tissue. Their role is not only in carrying blood (irrigating and draining) in and out of these tissues like a complex pipe system, but also serving as a 'home' and transit system for cells of the immune system to organs and tissues including lymphoid sites, where the human defense systems are 'born', 'trained', 'reside', and 'work'.

\section{Garcia · J. D. Carter • Y. C. Lin $(\bowtie)$}

Department of Internal Medicine, Division of Rheumatology,

University of South Florida, Morsani College of Medicine, 12901

Bruce B. Downs Blvd, MDC 41, Tampa, FL 33612, USA

e-mail: ylin2@health.usf.edu

C. Garcia

e-mail: cgarci11@health.usf.edu

J. D. Carter

e-mail: jocarter@health.usf.edu
Aberrant and dysregulated inflammation of these vessels, or vasculitis, results in narrowing of the vessel's lumen (i.e., stenosis) or aneurysmal wall damage (i.e., sac-like deformity of the vessel wall). This heterogenous group of conditions is rare. Our focus is on the role that infections may play in blood vessel inflammation, i.e., vasculitis.

\section{Microbiome and Autoimmunity}

The understanding of immunopathogenetic mechanisms of many diseases is ever expanding, and in the past few years, so has the understanding of the role of the microbiome and infections in eliciting immunologic responses, disease pathogenesis, metabolism, and prevention of autoimmunopathogenesis. The precise role of microbiota in disease processes is yet to be determined, but poses an interesting new field of research because of the potential for autoimmune or allergy pathology if disrupted or unbalanced. To understand the potential role that bacteria and the microbiome might play in vasculitis, it is important to review what is known about this relationship in other inflammatory diseases.

There are specific diseases in which microbiome disruption (dysbiosis) is linked to the pathogenesis, for example, chronic inflammatory bowel disease (IBD), celiac disease, multiple sclerosis, and asthma. More recently, there have been proposed links to cardiovascular disease, obesity, metabolic syndrome, type 1 diabetes mellitus, and rheumatoid arthritis (RA). $[1,2,3 \cdot \bullet]$ In other instances, specific infections and the homeostatic disruption caused by these infections are wellknown etiologies for diseases, such as Whipple disease, reactive arthritis, and hepatitis-C related vasculitis.

The microbiota is defined as the collection of commensal microorganisms (bacteria, fungi, viruses, protozoa) that resides in a larger multicellular host, in our case the human body. These organisms colonize the skin, mouth, gut, and 
vagina soon after birth. [3••] The normal adult microbiota of humans or mice consists of diverse species reaching densities of up to $10^{12}$ bacteria per gram content in the large intestines alone. [1] It is estimated that this microbiota outnumbers human cells by 10 -fold [4].

Several studies have attributed protective or proarthritogenic roles to Gram-negative enterobacteria (strains of Escherichia coli and Bacteroides species) when introduced into otherwise germ-free (GF) arthritis-prone rats. [2, 5-8] Other studies have revealed the importance of the microbiome including that of Round et al., who studied GF (or sterile) mice and found that those mice without pathogenic and beneficial microorganisms had poor gut-associated lymphoid tissue, fewer and smaller Peyer's patches and mesenteric lymph nodes, and under-developed isolated lymph nodes. In these GF mice, intestinal epithelial cells, which line the gut and form a physical barrier between the luminal surface contents (including the microbiota) and the underlying cells of the immune system, may have alterations in their many immunologic functions, such as secretion of cytokines, expression of major histocompatibility complex molecules, Toll-like receptors (TLRs), and a profound reduction in levels of secretory immunoglobulin A (IgA, one of the first defense mechanisms in the gut), among others. Hence, these GF mice are more susceptible to infections by certain pathogens. Microbiota in the gut contributes to TLR signaling, resulting in the development of T-helper (Th) 17 cells, that produce various proinflammatory cytokines including interleukin (IL)-17A, IL-17F, IL-21, and IL-22, and tumor necrosis factor (TNF)- $\beta$. Th17 cells affect a broad range of immune and non-immune cells, playing a mayor role in the homeostasis of the gut cells and antibody formation. Th17 cells are implicated in inflammatory conditions such as RA, psoriasis, psoriatic arthritis, ankylosing spondylitis, and multiple sclerosis. Studies suggest that different subsets of Th17 can be induced by different microorganisms, resulting in diverse effects. For example, filamentous bacteria can induce Th17 cells that benefit mucosal immunity, as opposed to pathogenic Bacteroides fragilis that can induce Th17-promoting colitis (colon inflammation) and tumor formation $[3 \cdot \bullet, 9 \cdot \bullet, 10,11]$.

RA is a disease characterized by inflammation of the tissue (synovial membrane) that lines the joints, leading to invasion and subsequent destruction (if left untreated) of the joint cartilage and bone. A review of historical texts, epidemiologic studies, and paleopathologic studies suggests that RA (as well as other inflammatory and autoimmune diseases) is a relatively new disease when compared with gout and osteoarthritis. Researchers hypothesize that its appearance and geographic predominance may be, in part, caused by transmissible pathogens found in oral and intestinal flora as a direct consequence of a Western lifestyle and obesity. Periodontal pathogens such as Porphyromonas gingivalis have been associated with and may explain autoantibody formation and joint inflammation underlying RA. [2, 12] The plaque biofilm formed by organisms associated with periodontal disease (such as gingivitis) stimulates the immune cells within the oral cavity, resulting in the release of cytokines such as IL- $1 \beta$, TNF- $\alpha$, and IL-6, resulting in the production of collagenolytic enzymes such as matrix metalloproteinases. Cathepsins and osteoclast activation contribute to bone resorption, and macrophage colonystimulating factor is also involved. Other microbial factors presumably involving the inflammatory pathogenesis are bacterial DNA, CpG motifs, heat shock proteins (HSP), and lipopolysaccharides. Microbiota can also affect regulatory $\mathrm{T}$ cells (Treg), which are essential for maintaining gut homeostasis, through immunosuppressive cytokines (IL-10, IL-35), and inhibition of effector T cells. Some studies have shown that commensal bacteria can induce $\mathrm{CD} 4+\mathrm{T}$ cells, which differentiate into Treg that enforce bacteria-specific immune tolerance. Defects related to these Treg are associated with IBD, RA, psoriasis, and multiple sclerosis [12-17].

Another subset of inflammatory arthritides classically associated with gut dysbiosis is spondyloarthritides (arthritis commonly affecting the spine and peripheral joints including IBD-related arthritis and reactive arthritis), Whipple disease (Thropheryma whipplei present in the small intestine), and jejunoileal bypass-associated arthritis $[2,18,19]$.

Reactive arthritis (formerly known as Reiter syndrome and/ or Fiessinger-Leroy syndrome), a type of spondyloarthritis, arises after certain types of gastrointestinal (Salmonella, Shigella, Campylobacter, and Yersinia) or genitourinary infections (Chlamydia trachomatis) in genetically susceptible persons. Other pathogens have been described, such as Chlamydophila pneumonia (respiratory tract), Ureaplasma ueralyticum, Helicobacter pylori, E. coli, and Clostridium difficile. The shared feature of these Gram-negative bacteria pathogens is the lipopolysaccharide cell wall component. In Chlamydia-induced reactive arthritis specifically, HSP, especially HSP-60, are a hallmark feature of the persistent form of this synovial-based organism. These HSPs appear to play a key role in the immunogenesis by preventing apoptosis [18]. TLRs also play an important role in reactive arthritis as they recognize the pathogens and activate the immune cell response. Specifically, TLR-4 recognizes the LPS of the microbial cell wall [18, 20-23].

\section{Role of Infectious Agents in Vasculitis}

The term vasculitis is used to refer to necrotizing or nonnecrotizing inflammation of the blood vessel walls, which can result in damage to the affected vessels and also the end organs, i.e., those that are irrigated or supplied by the inflamed vessel. For example, kidney failure results if the renal vessels are affected, and lung hemorrhage or inflammation result if the pulmonary vasculature is affected. If the blood vessel is 
imagined as a tube or cylinder, the inner wall directly in contact with the blood flow is the intima lined with endothelial cells, followed outwardly by the media, with the adventitia forming the most external layer of this tube.

The large group of systemic diseases that comprise the vasculitides is heterogeneous, but they are considered to have a common autoimmune pathogenic process with overlapping features. These conditions have been studied as early as 1554 when Antoine Saporta described inflammation and aneurysmal dilation of the aorta secondary to syphilis [24].

Depending on the presence of a known underlying inflammatory process or primary rheumatologic disorder, the vasculitides can be referred to as primary (e.g., granulomatosis with polyangiitis, formerly known as Wegener granulomatosis) and secondary (e.g., vasculitis secondary to systemic lupus, RA, infections, drugs, or malignancy). Despite being called primary vasculitis, the exact mechanisms responsible for unleashing the autoimmune cascade involving the complex immunopathology including upregulation of major histocompatibility complex class II antigens, expansion of $\mathrm{T}$ cells, and production of cytokines, is poorly understood. Infections have been hypothesized to play a role $[23,25,26,27 \bullet]$.

The mechanisms by which pathogens result in vascular inflammation can be separated into two categories: one is by direct pathogen invasion of the vessel wall; the other is by immune-mediated injury to the vessel wall. Microorganisms can produce direct wall damage by inducing smooth muscle cell (SMC) proliferation and migration, inhibiting apoptosis of the SMCs; endothelial dysfunction (induction of procoagulants, inhibition of vessel dilation); and increasing reactive oxygen species, cytokines, chemokines, and cellular adhesion molecules. These changes are seen in atherosclerotic disease as well as vasculitis. The proposed mechanisms of immune-mediated vascular damage induced by microorganisms include a complex interaction involving immune complexes, molecular mimicry, secretion of cytokines, superantigens, anti-neutrophil cytoplasmic antibodies (ANCAs), autoantigen complementarity, and T-cell-mediated damage $[23,28]$. These mechanisms are discussed later.

Diagnostic criteria for clinical use are lacking for this rare group of rheumatologic disorders. The 1990 American College of Rheumatology (ACR) Criteria for the Classification of Vasculitis [29] was intended to differentiate seven forms of adult vasculitides based on clinical and laboratory findings. However, these were intended primarily for research purposes. Later in 1994, the Chapel Hill Consensus Conference (CHCC) on the Nomenclature of Systemic Vasculitis expanded on the ACR criteria, by grouping the vasculitides according to the size of the predominantly affected blood vessels (small, medium, or large), underlying histoimmunopathology (i.e., whether granulomas, necrotizing inflammation, or IgA deposits were found, to name a few), and the presence of ANCAs (autoantibodies mainly IgG type directed against the cytoplasm of neutrophils and to a lesser extent monocytes) with the purpose of finding appropriate nomenclature for the most common type of primary vasculitides [30].

In 2012, the CHCC convened again to expand on the original nomenclature, to include secondary forms of vasculitides, and replace wherever possible eponyms with new terminology that would better reflect the underlying pathophysiology [31, 32].

This CHCC nomenclature excludes infectious vasculitis; those that have an established purely infectious cause such as rickettsial vasculitis, syphilitic aortitis, and Apergillus arteritis, but does include those vasculitic processes in which an infection has unleashed a potentiated immunologic response, e.g., hepatitis $\mathrm{C}$ cryoglobulinemia [31].

It is not yet known why some vessels are affected and others are not, or why even those of the same caliber can be unequally injured. It is possible that the embryonic origins of the endothelial cells, as well as the type of organ parenchymal cells and distinct substrates may determine the pattern of susceptibility. Other factors that are thought to determine the variability in cellular response to injury are the different membrane proteins, such as adhesion molecules and TLRs of the dendritic cells [25].

Following the 2012 CHCC nomenclature, we discuss the major adult vasculitides according to the predominantly affected blood vessels (small, medium, and large, keeping in mind that any category can affect any size artery), common histopathology, shared immunologic mechanisms, and common perceived infectious associations when present.

\section{Large-Vessel Vasculitides}

Takayasu arteritis and giant cell arteritis (GCA, also known as temporal arteritis) both affect the large blood vessels, meaning the aorta and its major branches, none of which are inside organs. Their pathogenesis differs though, in that GCA is a granulomatous type of inflammation typically found in older persons, and affecting more peripheral blood vessels, such as the third to fifth branches of the aorta; whereas Takayasu arteritis typically affects a younger population, occurring in the aorta and its primary branches, and granulomas are not a part of the histopathology. However, recent evidence suggests both could be just different manifestations of vessel involvement within the same spectrum of disease. Because the larger vessels are more challenging to sample (e.g., the aorta in a young patient affected by Takayasu arteritis), and because the large-vessel vasculitis model is more difficult to reproduce in small animals, more is known about GCA, as samples from the temporal artery are easily accessible and routinely biopsied. Despite temporal artery biopsies being more readily available, many of the studies on candidate pathogens for 
GCA are small cohorts using targeted methods and have not been reproduced $[33,34 \bullet]$.

The location within the arterial vessel wall where the immune reaction occurs, the adventitia, is composed of dendritic cells, endothelial cells, vascular SMCs, elastic membranes, matrix, and fibroblasts; these interact with other parts of the immune system, composed of T cells and macrophages, mediated by cytokines, IL-6, IL-17, IL-12, and interferon- $\gamma$. It is thought that, in vasculitis lesions, the TLRs in the dendritic cells recognize antigenic lipopolysaccharides (present in Gram-negative bacteria), thereby activating the dendritic cells. CD4+ $\mathrm{T}$ cells are recruited to the affected vessels, as are macrophages. It is these macrophages that when highly activated and aggregated are called histiocytes and arrange themselves into granulomas surrounded by T cells. Another component of this is HSP, which induce TNF- $\alpha$ by macrophages, and IL-1 messenger RNA and IL- 6 expression by endothelial cells and SMCs [23, 33, 35-37].

A 1999 study suggests a role of parvovirus B19 in GCA, after a statistically significant amount of temporal artery biopsies was positive for parvovirus B19 DNA polymerase chain reaction analysis. Although the authors mention that this link may be etiologic, a coincidental co-infection could not be ruled out entirely, and larger subsequent studies have not confirmed earlier reports [23, 38].

Because GCA tends to affect older persons and this population tends to have latent herpesvirus infections, and because varicella zoster virus can lead to T-cell-mediated inflammation, this virus has been deemed a potential trigger. In a 2001 study, Mitchel et al. detected varicella zoster virus DNA in statistically significant, temporal artery biopsy samples, compared with controls, but at the same time the virus was present in low quantities, abortively replicating or found to be latent, and therefore a clear etiology could not be established. Negative studies have been reported for cytomegalovirus, Epstein-Barr virus, HHV-6, HHV-7, and HHV-8. [23, 39-42] Very recently, another organism with a possible association with GCA is a Burkholderia-like bacterium (named Bp-GCA) that has been isolated from temporal artery biopsies in patients with GCA, using $16 \mathrm{~S}$ ribosomal RNA gene sequencing. Further studies are required to expand on this topic [43].

Bhatt et al. did not find any consistent pathogen associated with GCA after performing DNA sequencing of the temporal artery biopsy specimens in patients with GCA. Propionibacterium acnes and E. coli were identified in 16 of 17 samples (the 17 samples included 12 GCA and five control samples), and Moraxella catarrhalis in one control sample [34•].

No solid evidence has supported an association between streptococcal, mycobacterial, and spirochete infections in Takayasu arteritis, although recent studies have shown a correlation between mycobacterial HSP-65 and human HSP-60 reactive T cells, suggesting an infectious etiology [44, 45].
Currently, the cornerstone of treatment for large-vessel vasculitis (i.e., GCA, Takayasu arteritis) remains glucocorticoids, which aim to halt the progression of the inflammatory insult to the vessel wall. Anti-metabolite treatments (e.g., methotrexate, cyclophosphamide) have also been used in cases that are resistant to glucocorticoid therapy. Biologic therapies, particularly anti-TNF inhibitors (e.g., infliximab), have shown efficacy in controlling refractory cases of Takayasu arteritis. More recently, an anti-IL-6 inhibitor (e.g., tocilizumab) has been reported to be a promising treatment for large-vessel vasculitides. [46] While all the therapies can be effective in symptomatic relief of vascular inflammation, the limited knowledge on the etiopathogenesis or substrate of large-vessel vasculitides hinders the development of targetspecific treatment or better preventative remedies.

\section{Medium- and Small-Vessel Vasculitides}

Polyarteritis nodosa (PAN) and mixed cryoglobulinemia are classic examples of virus-associated vasculitis due to hepatitis $B$ virus (HBV) and hepatitis $\mathrm{C}$ virus (HCV), respectively. PAN is a rare necrotizing inflammation of medium-sized artery walls that leads to aneurysm formation. In a number of patients, it is due to $\mathrm{HBV}$ infection, with a declining incidence owing to the screening of blood products, and vaccinations. In PAN, HBV induces immune complex deposition on the vessel walls, resulting in vessel damage mediated by activation of the complement pathway, coagulation cascade, activation of endothelial cells, and chemotaxis (attraction) of other inflammatory cells. Treatment of the viral infection halts the viral replication thereby halting the autoimmune mechanism, while also allowing for immunosuppressive treatment to be instated. This has resulted in improved prognosis for virus-associated PAN [23, 27•].

Others have suggested that microbes associated with PANlike syndromes include streptococcal species, Klebsiella, Pseudomonas, Yersinia, Toxoplasma gondii, and rickettsia, among others. A form of limited cutaneous PAN has been associated with streptococcal infection, and Mycobacterium fortiutum $[44,47,48]$.

The human immunodeficiency virus can cause necrotizing inflammation of any size vessel; this rare manifestation can resemble either GCA, Kawasaki, PAN, or small-vessel vasculitis. It may arise from the infection itself (possibly due to an excess of CD8 cells) or secondary to an opportunistic infection (when CD4 T cells are $<200$ cells/mL) such as cytomegalovirus, varicella zoster virus, Toxoplasma gondii, and Pneumocystis jiroveci [49-51].

Small-vessel vasculitides is another heterogeneous subset characterized by the presence of ANCA-induced activation of neutrophils and monocytes, resulting in inflammation of vascular and extravascular sites. It is currently believed that an 
inflammatory stimulus (e.g., infection, drugs) primes circulating neutrophils and monocytes to display these autoantigen ANCAs at or near the cell surface, and the interaction between the antigen and ANCA results in neutrophil activation and the inflammatory cascade that ensues. Another theory, known as the autoantigen complementarity, proposes that microbial structures complementary to ANCA can elicit similar responses [23].

Small-vessel vasculitides can be further categorized. The first type is granulomatosis with polyangiitis (GPA, formerly known as Wegener granulomatosis) if there is histologic evidence of granulomatous inflammation without asthma history. In microscopic polyangiitis (MPA), there is no granulomatosis or history of asthma. Eosinophilic granulomatosis with polyangiitis (EGPA, also known as Churg Strauss syndrome) includes granulomatosis with a history of asthma with or without peripheral blood eosinophilia. [31, 52] Certain clinical features also help differentiate the different subtypes of small-vessel vasculitis.

Two main autoantigen targets of ANCA are identified; myeloperoxidase and proteinase 3 (PR3). Others include elastase-specific ANCAs described in ANCA vasculitis secondary to levamisole-laced cocaine, and lysosomal-associated membrane protein 2 (LAMP-2) ANCAs, which in a study by Kain et al. was present in pauci-immune necrotizing glomerulonephritis (a form of vasculitis limited to the kidney) [52-55].

The induction of pathogenic ANCAs is likely multifactorial, in that a combination of a stimulus (infection or drug) in the setting of impaired immune regulation and/or suppression triggers an autoimmune response or dysregulation of genomic expression of autoantigens resulting in vascular inflammation. [52] Several microbes have been implicated in the induction of ANCA vasculitis, such as Staphylococcus aureus and Ross River virus. However, it is thought that there is an immunologic response to autoantigen complementary peptide structures within these organisms, in patients with genetic, human leukocyte antigen-binding sites that recognize these complementary proteins (e.g., HLA DRB1*15 allele is overrepresented in African American patients with PR3-ANCAassociated disease). It has been proposed that Staphylococcus aureus express superantigens, proteins that can stimulate large numbers of $\mathrm{T}$ cells, and may also stimulate B cells. $[23,52$, 56-60] Some data support infectious triggers for GPA but not MPA, in light of the cyclical incidence pattern; identification of nasal carriage of $S$. aureus in patients with GPA relapse [61].

In an aforementioned study by Kain et al., there was microbiologically confirmed infection with fimbriated pathogens (E. coli and K. pneumoniae) in $69 \%$ of the patients, weeks before presentation with pauci-immune necrotizing glomerulonephritis. [55] The murine experiment was based on the premise that the bacterial adhesion FimH has complete homology with the human LAMP-2 epitope, which in turn cross-reacts with ANCAs. Thus, rats immunized with FimH resulted in necrotizing glomerulonephritis resembling ANCAassociated glomerulonephritis in humans. [55] This experimental murine model was unable to be reproduced by Roth et al. in humans [62].

Though in some instances the causal association between infection and vasculitis is clear, the reasons why these infections have tropism to the vascular tissues they affect are less apparent. Organisms can use distinct proteins and structures that allow for adhesion and attachment to gain cell entry. The parenchymal cells that characterize each organ containing the endothelial cells may have defense mechanisms to promote or limit these infections once they have gained cell entry, e.g., defensins, cathelicidins [25].

In experimental murine models, infections with gamma herpesvirus 68 or cytomegalovirus were demonstrated in those mice with defects in the interferon- $\gamma$ pathway. Persistent viral replication resulted in inflammation of the aorta, and in a post-mortem analysis, clearance of the virus occurred with the exception of the vascular SMCs of the aortic root, which may be because of the site-specific immune response of this vessel [63-65].

Current therapeutic management of small-vessel vasculitis (e.g., GPA, MPA, EGPA) includes the induction of remission using immunosuppressive agents including cyclophosphamide, rituximab, or methotrexate. These are used in conjunction with high-dose corticosteroids. Once remission is achieved, maintenance of remission is achieved by using less toxic immunosuppressive therapies such as azathioprine, methotrexate, or mycophenolate mofetil. Similar to large-vessel vasculitides, there are no target-specific treatments that address the pathogenic cause of the disease. Interestingly, long-term use of trimethoprim-sulfamethoxazole (Bactrim) has been shown to prevent the relapse of upper airway regions in GPA patients. Although it was not clear how the antibiotic exerts its effect, some postulated it could be attributed to a reduction in nasal and upper airway colonization of $S$. aureus.

$\mathrm{HCV}$ can cause cryoglobulinemia, which in turn may result in necrotizing vasculitis of the small-sized vessels of the skin, peripheral nerves, and renal glomerulus; it also affects the lung, gastrointestinal tract, and medium-sized vessels. Cryoglobulinemia can occur in up to $40-60 \%$ of infected patients, and vasculitis can occur in less than $5 \%$ of infected patients. [66] The mechanisms by which HCV and cryoglobulins result in vasculitis might involve predilection of IgM RF for the mesangial matrix, antibody-specific complement-mediated mechanisms, resulting in vascular adhesion molecule up-regulation and platelet aggregation and up- 
regulation in the expression of TLR 3 and mRNA for chemokines, which in turn may attract inflammatory cells (lymphocytes, monocytes). [25, 67, 68] As in HBV-related PAN, the HCV-associated cryoglobulinemic vasculitis treatment consists of antiviral agents along with traditional immunosuppressants (corticosteroids and rituximab, an anti-CD20 monoclonal antibody), and plasma exchange [27•].

\section{Other Infections Resulting in Vasculitis}

Other organisms implicated in vasculitis include cytomegalovirus, erythrovirus B19 (formerly parvovirus B19), varicella zoster virus, human T-cell lymphotrophic virus-1, Mycobacterium tuberculosis, and syphilis. The latter two classically affect the aorta, resulting in aortitis. Aortitis and cerebrovascular disease associated with syphilis and rickettsial diseases can mimic the aforementioned primary systemic vasculitides. In particular, intracellular pathogens such as mycobacteria and fungi can elicit granulomatous inflammation mediated by $\mathrm{CD} 4+\mathrm{T}$ cells and macrophages, similar to that seen in GPA and GCA [23, 51, 69-75].

\section{Conclusion}

With the exception of the well-established associations between infections and vasculitis (HBV- and HBS-associated vasculitis), and infections and other inflammatory conditions (e.g., reactive arthritis), the role of the microbiome and infections in the primary vasculitides remains largely unknown. The immunopathology is well described in many of the vasculitides, but how this process is triggered, and the reason for site-specific inflammation is poorly understood. The quest to determine specific bacterial etiologic triggers has been hampered by several factors. Reproducing these vasculitides in animal models is difficult and often may not be feasible, retrieval of an organism in affected organ tissues does not prove causality, and contamination of biopsy specimens may result in confounding results. This is a constantly evolving and expanding field that shows promise. Identifying infectious triggers can aid in prevention and in the improvement of treatment modalities.

\section{Compliance with Ethics Guidelines}

Conflict of Interesting Statement Drs. Garcia, Carter, and Lin each declare that there are no conflicts of interest.

Human and Animal Rights and Informed Consent This article contains no studies with human or animal subjects performed by any of the authors.

\section{References}

Papers of particular interest, published recently, have been highlighted as:

- Of importance

-. Of major importance

1. Geuking MB, Koller Y, Rupp S, McCoy KD. The interplay between the gut microbiota and the immune system. Gut Microbes. 2014;5(3):1-8.

2. Scher JU, Abramson SB. The microbiome and rheumatoid arthritis. Nat Rev Rheumatol. 2011;7(10):569-78.

3.• Karczewski J, Poniedzialek B, Adamski Z, Rzymski P. The effects of the microbiota on the host immune system. Autoimmunity. 2014: 1-11. Reviews the host-microbiota interactions, specifically on the influence of bacterial-derived signals on immune cell function and the mechanisms by which these signals modulate the development and progression of inflammatory and autoimmune diseases.

4. Turnbaugh PJ, Ley RE, Hamady M, Fraser-Liggett CM, Knight R, Gordon JI. The human microbiome project. Nature. 2007;449(7164):804-10.

5. Kohashi O, Kohashi Y, Takahashi T, Ozawa A, Shigematsu N. Reverse effect of Gram-positive bacteria vs. Gram-negative bacteria on adjuvant induced arthritis in germfree rats. Microbiol Immunol. 1985;29(6):487-97.

6. Kohashi O, Kohashi Y, Takahashi T, Ozawa A, Shigematsu N. Suppressive effet of Escherichia coli on adjuvant-induced arthritis in germ-free rats. Arthritis Rheum. 1986;29(4):547-53.

7. Rath HC, Herfarth HH, Ikeda JS, Grenther WB, Hamm Jr TE, Balish E, et al. Normal luminal bacteria, especially Bacteroides species, mediate chronic colitis, gastritis and arthritis in HLAB27/human beta2 mciroglobulin transgenic rats. J Clin Invest. 1996;98(4):945-53.

8. Sinkorova Z, Capkova J, Niederlova J, Stepankova R, Sinkora J. Commensal intertinal bacterial strains trigger ankylosing enthesopathy of the ankle in inbred B10.BR (H-2(k)) male mice. Hum Immunol. 2008;69(12):845-50.

9.• Round JL, Mazmanian SK. The gut microbiota shapes intestinal immune responses during health and disease. Nat Rev Immunol. 2009;9:313-23. Discusses the impact of gut microbiota to the adaptive immune system and highlights the pathways that regulate homeostasis.

10. Ivanov II, Atarashi K, Manel N, et al. Induction of intestinal Th17 cells by segmented filamentous bacteria. Cell. 2009;139:485-98.

11. Sakaguchi S, Yamaguchi T, Nomura T, Ono M. Regulatory T cells and immune tolerance. Cell. 2008;133:775-87.

12. Loyola-Rodriguez JP, Martinez-Martinez RE, Abud-Mendoza C, Patino-Marin N, Seymour GJ. Rheumatoid arthritis and the role of oral bacteria. J Oral Microbiol. 2010;2:5784.

13. Albani S, Carson DA, Roudier J. Genetic and environmental factors in the immune pathogenesis of rheumatoid arthritis. Rheumatol Dis Clin N Am. 1992;18:729-40.

14. Deng G, Tarkowski A. The role of bacterial DNA in septic arthritis. Int J Mol Med. 2000;6:29-33.

15. Deng G, Tarkowski A. The features of arthritis induced by $\mathrm{CpG}$ motifs in bacterial DNA. Arthritis Rheum. 2000;43:356-64.

16. Lathrop SK, Bloom SM, Rao SM, Nutsch K, Lio CW, Santacruz N, et al. Peripheral education of the immune system by colonic commensal microbiota. Nature. 2011;478(7368):250-4.

17. Cebula A, Seweryn M, Rempala GA, Pabla SS, McIndoe RA, Denning TL, et al. Thymus-derived regulatory $\mathrm{T}$ cells contribute to tolerance to commensal microbiota. Nature. 2013;497(7448): 258-62. 
18. Carter JD, Hudson AP. Reactive arthritis: clinical aspects and medical management. Rheumatol Dis Clin N Am. 2009;35(1):2144.

19. Ross CB, Scott HW, Pincus T. Jejunoileal bypass arthritis. Baillieres Clin Rheumatol. 1989;3(2):339-55.

20. Zugel U, Kaufmann SH. Role of heat shock proteins in protection from and pathogenesis of infectious diseases. Clin Microbiol Rev. 1999;12(1):19-39.

21. Zugel U, Kaufmann SH. Immune response against heat shock proteins in infectious diseases. Immunobiology. 1999;201(1):2235 .

22. Dean D, Powers VC. Persistent Chlamydia trachomatis infections resist apoptotic stimuli. Infect Immun. 2001;69(4):2442-7.

23. Rodriguez-Pla A, Stone JH. Vasculitis and systemic infections. Curr Opin Rheumatol. 2006;18(1):39-47.

24. Hoffman GS, Langford CA, Weynard CM, Goronzy JJ. Inflammatory diseases of blood vessels. 2nd ed. West Sussex, UK: Wiley-Blackwell; 2012.

25. Hoffman GS, Calabrese LH. Vasculitis: determinants of disease patterns. Nature Rev Rheumatol. 2014;10(8):454-62.

26. Della Rossa A, Cioffi E, Elefante E, Ferro F, Parma A, Vagelli R, et al. Systemic vasculitis: an annual critical digest of the most recent literature. Clin Exp Rheumatol. 2014;32(3 Suppl 82):S98-105.

27. Guillevin L. Infections in vasculitis. Best Pract Res Clin Rheumatol. 2013;27(1):19-31. Discusses the different infectious causes of vasculitits.

28. Ross R. The pathogenesis of atherosclerosis: a perspective for the 1990s. Nature. 1993;362(6423):801-9.

29. Calabrese LH, Michel BA, Bloch DA, Arend WP, Edworthy SM, Fauci AS, et al. The American College of Rheumatology 1990 criteria for the classification of hypersensitivity vasculitis. Arthritis Rheum. 1990;33(8):1108-13.

30. Jennette JC, Falk RJ, Andrassy K, Bacon PA, Churg J, Gross WL, et al. Nomenclature of systemic vasculitides: proposal of an international consensus conference. Arthritis Rheum. 1994;37(2):18792.

31. Jennette JC, Falk RJ, Bacon PA, Basu N, Cid MC, Ferrario F, et al. 2012 revised International Chapel Hill Consensus Conference Nomenclature of Vasculitides. Arthritis Rheum. 2013;65(1):1-11.

32. Jennette JC. Overview of the 2012 revised International Chapel Hill Consensus Conference nomenclature of vasculitides. Clin Exp Nephrol. 2013;17(5):603-6.

33. Weyand CM, Goronzy JJ. Immune mechanisms in medium and large-vessel vasculitis. Nat Rev Rheumatol. 2013;9(12):731-40.

34. Bhatt AS, Manzo VE, Pedamallu CS, Duke F, Cai D, Bienfang DC, et al. Brief report: in search of a candidate pathogen for giant cell arteritis: sequencing-based characterization of the giant cell arteritis microbiome. Arthritis Rheum. 2014;66(7):1939-44. Characterized the microbiome of the temporal artery using DNA sequencing of temporal artery biopsy specimens from GCA patients versus nonGCA controls, in an attempt to isolate possible candidate pathogen (s) causing vasculitis.

35. Stenmark KR, Yeager ME, El Kasmi KC, Nozik-Grayck E, Gerasimovskaya EV, Li M, et al. The adventitia: essential regulator of vascular wall structure and function. Annu Rev Plant Physiol Plant Mol Biol. 2013;75:23-47.

36. Ma-Krupa W, Jeon MS, Spoerl S, Tedder TF, Goronzy JJ, Weyand CM. Activation of arterial wall dendritic cells and breakdown of self-tolerance in giant cell arteritis. J Exp Med. 2004;199(2):17383.

37. Krupa WM, Dewan M, Jeon MS, Kurtin PJ, Younge BR, Goronzy JJ, et al. Trapping of misdirected dendritic cells in the granulomatous lesions of giant cell arteritis. Am J Pathol. 2002;161(5):181523.

38. Gabriel SE, Espy M, Erdman DD, Bjornsson J, Smith TF, Hunder GG. The role of parvovirus B19 in the pathogenesis of giant cell arteritis: a preliminary evaluation. Arthritis Rheum. 1999;42(6): 1255-8.

39. Mitchell BM, Font RL. Detection of varicella zoster virus DNA in some patients with giant cell arteritis. Invest Ophthalmol Vis Sci. 2001;42(11):2572-7.

40. Helweg-Larsen J, Tarp B, Obel N, Baslund B. No evidence of parvovirus B19, Chlamydia pneumoniae or human herpes virus infection in temporal artery biopsies in patients with giant cell arteritis. Rheumatology (Oxford, England). 2002;41(4):445-9.

41. Rodriguez-Pla A, Bosch-Gil JA, Echevarria-Mayo JE, RosselloUrgell J, Solans-Laque R, Huguet-Redecilla P, et al. No detection of parvovirus B19 or herpesvirus DNA in giant cell arteritis. J Clin Virol. 2004;31(1):11-5.

42. Alvarez-Lafuente R, Fernandez-Gutierrez B, Jover JA, Judez E, Loza E, Clemente D, et al. Human parvovirus B19, varicella zoster virus, and human herpes virus 6 in temporal artery biopsy specimens of patients with giant cell arteritis: analysis with quantitative real time polymerase chain reaction. Ann Rheum Dis. 2005;64(5):780-2.

43. Koening CL KB, Hernandez-Rodriguez J, Corbera-Bellalta M, Cid $\mathrm{MC}$, Schweizer HP, et al. Identification of a Burkholderia-like strain from temporal arteries of subjects with giant cell arteritis [abstract]. American College of Rheumatology Annual Meeting. 2012.

44. Somer T, Finegold SM. Vasculitides associated with infections, immunization, and antimicrobial drugs. Clin Infect Dis. 1995;20(4):1010-36.

45. Kumar Chauhan S, Kumar Tripathy N, Sinha N, Singh M, Nityanand S. Cellular and humoral immune responses to mycobacterial heat shock protein-65 and its human homologue in Takayasu's arteritis. Clin Exp Immunol. 2004;138(3):547-53.

46. Unizony S, Arias-Urdaneta L, Miloslavsky E, Arvikar S, Khosroshahi A, Keroack B, et al. Tocilizumab for the treatment of large-vessel vasculitis (giant cell arteritis, Takayasu arteritis) and polymyalgia rheumatica. Arthritis Care Res (Hoboken). 2012;64(11):1720-9.

47. Stein RH, Phelps RG, Sapadin AN. Cutaneous polyarteritis nodosa after streptococcal necrotizing fasciitis. Mount Sinai J Med. 2001;68(4-5):336-8.

48. Chen HH, Hsiao CH, Chiu HC. Successive development of cutaneous polyarteritis nodosa, leucocytoclastic vasculitis and Sweet's syndrome in a patient with cervical lymphadenitis caused by Mycobacterium fortuitum. Br J Dermatol. 2004;151(5):1096-100.

49. Gisselbrecht M, Cohen P, Lortholary O, Jarrousse B, Gayraud M, Gherardi R, et al. HIV-related vasculitis: clinical presentation and therapeutic approach on six patients. AIDS (London, England). 1997;11(1):121-3.

50. Guillevin L. Vasculitides in the context of HIV infection. AIDS (London, England). 2008;22 Suppl 3:S27-33.

51. Pagnoux C, Cohen P, Guillevin L. Vasculitides secondary to infections. Clin Exp Rheumatol. 2006;24(2 Suppl 41):S71-81.

52. Jennette JC, Falk RJ. Pathogenesis of antineutrophil cytoplasmic autoantibody-mediated disease. Nature Rev Rheumatol. 2014;10(8):463-73.

53. Pendergraft WF, Niles JL. Trojan horses: drug culprits associated with antinuetrophil cytoplasmic autoantibody (ANCA) vasculitis. Curr Opin Rheumatol. 2014;26(26):42-9.

54. Graf J. Rheumatic manifestations of cocaine use. Curr Opin Rheumatol. 2013;25(25):50-5.

55. Rea K. Molecular mimicry in pauci-immune focal necrotizing glomerulonephritis. Nat Med. 2008;14(14):1088-96.

56. Popa ER, Stegeman CA, Kallenberg CG, Tervaert JW. Staphylococcus aureus and Wegener's granulomatosis. Arthritis Res. 2002;4:77-9.

57. Mea L. Nasal carriage of Staphylococcus aureus and endonasal activity in Wegener's granulomatosis as compared to rheumatoid arthritis and chronic rhinosinusitis with nasal polyps. Clin Exp Rheumatol. 2010;28 Suppl 57:51-5. 
58. Davies DJ, Moran JE, Niall JF, Ryan GB. Segmental necrotizing glomerulonephritis with antineutrophi antibody: possible arbovirus aetiology? Br Med J (Clin Res Ed). 1982;285:606.

59. Preston GA, Pendergraft WF, Falk RJ. New insights that link microbes with the generation of antineutrophil cytoplasmic autoantibodies: the theory of autoantigen complementarity. Curr Opin Nephrol Hypertens. 2005; 14:217-22.

60. Yea C. DRB $1 * 15$ allele is a risk factor for P3-ANCA disease in African Americans. J Am Soc Nephrol. 2011;22:1161-7.

61. Khan I, Watts RA. Classification of ANCA-associated vasculitis. Curr Rheumatol Rep. 2013;15(12):383.

62. Roth AJ, Brown MC, Smith RN, Badhwar AK, Parente O, Chung $\mathrm{Hc}$, et al. Anti-LAMP-2 antibodies are not prevalent in patients with antineutrophil cytoplasmic autoantibody glomerulonephritis. J Am Soc Nephrol. 2012;23:545-55.

63. Weck KE, Dal Canto AJ, Gould JD, O'Guin AK, Roth KA, Saffitz JE, et al. Murine gamma-herpesvirus 68 causes severe large-vessel arteritis in mice lacking interferon-gamma responsiveness: a new model for virus-induced vascular disease. Nat Med. 1997;3(12): 1346-53.

64. Presti RM, Pollock JL, Dal Canto AJ, O'Guin AK, Virgin HW. Interferon gamma regulates acute and latent murine cytomegalovirus infection and chronic disease of the great vessels. J Exp Med. 1998;188(3):577-88.

65. Dal Canto AJ, Swanson PE, O'Guin AK, Speck SH, Virgin HW. IFN-gamma action in the media of the great elastic arteries, a novel immunoprivileged site. J Clin Invest. 2001;107(2):R15-22.

66. Ferri C, Zignego AL, Pileri SA. Cryoglobulins. J Clin Pathol. 2002;55(1):4-13.
67. Fornasieri A, D'Amico G. Type II mixed cryoglobulinaemia, hepatitis $\mathrm{C}$ virus infection, and glomerulonephritis: nephrology, dialysis, transplantation. Nephrol Dial Transplant. 1996;11 Suppl 4:25-30.

68. Cacoub P, Ghillani P, Revelen R, Thibault V, Calvez V, Charlotte F, et al. Anti-endothelial cell auto-antibodies in hepatitis $\mathrm{C}$ virus mixed cryoglobulinemia. J Hepatol. 1999;31(4):598-603.

69. Gaa J, Weidauer S, Sitzer M, Lanfermann H, Zanella FE. Cerebral vasculitis due to Treponema pallidum infection: MRI and MRA findings. Euro Radiol. 2004;14(4):746-7.

70. Smith JL, Israel CW, Harner RE. Syphilitic temporal arteritis. Arch Ophthalmol. 1967;78(3):284-8.

71. Aizawa H, Hasegawa A, Arai M, Naganuma F, Hatori M, Kanda $\mathrm{T}$, et al. Bilateral coronary ostial stenosis and aortic regurgitation due to syphilitic aortitis. Intern Med (Tokyo, Japan). 1998;37(1):56-9.

72. Levy-Clarke GA, Buggage RR, Shen D, Vaughn LO, Chan CC, Davis JL. Human T-cell lymphotropic virus type-1 associated t-cell leukemia/lymphoma masquerading as necrotizing retinal vasculitis. Ophthalmology. 2002;109(9):1717-22.

73. De Micco C, Raoult D, Benderitter T, Gallais H, Toga M. Immune complex vasculitis associated with mediterranean spotted fever. J Infect. 1987;14(2):163-5.

74. Smith JL, Winward KE, Nicholson DF, Albert DW. Retinal vasculitis in Lyme borreliosis. J Clin Neuro-Ophthalmol. 1991;11(1):7-15.

75. Romi F, Krakenes J, Aarli JA, Tysnes OB. Neuroborreliosis with vasculitis causing stroke-like manifestations. Euro Neurol. 2004;51(1):49-50. 